\title{
Global Attractivity Results on Complete Ordered Metric Spaces for Third-Order Difference Equations
}

\author{
Mujahid Abbas ${ }^{1}$ and Maher Berzig ${ }^{2}$ \\ ${ }^{1}$ Department of Mathematics and Applied Mathematics, University of Pretoria, Lynnwood road, Pretoria 0002, South Africa \\ ${ }^{2}$ University of Tunisia, Tunis College of Sciences and Techniques, 5 Avenue Taha Hussein, BP 56, Bab Manara, Tunis, Tunisia \\ Correspondence should be addressed to Maher Berzig; maher.berzig@gmail.com
}

Received 24 October 2012; Accepted 31 January 2013

Academic Editor: Jacques Liandrat

Copyright (c) 2013 M. Abbas and M. Berzig. This is an open access article distributed under the Creative Commons Attribution License, which permits unrestricted use, distribution, and reproduction in any medium, provided the original work is properly cited.

We establish fixed-point theorems for mixed monotone mappings in the setting of ordered metric spaces which satisfy a contractive condition for all points that are related by a given ordering. We also give a global attractivity result for all solutions of the difference equation $u_{n+1}=F\left(u_{n}, u_{n-1}, u_{n-2}\right), n=2,3, \ldots$, where $F$ satisfies certain monotonicity conditions with respect to the given ordering. As an application of our obtained results, we present some iterative algorithms to solve a class of matrix equations. A numerical example is also presented to test the validity of the algorithms.

\section{Introduction}

The following global attractivity result from [1] (see also [2]) is very useful in establishing convergence results in many situations.

Theorem 1 (see [1]). Let $[a, b]$ be a closed and bounded interval of real numbers and let $F \in C\left([a, b]^{3},[a, b]\right)$ satisfy the following conditions.

(i) The function $F\left(z_{1}, z_{2}, z_{3}\right)$ is monotonic in each of its arguments.

(ii) For each $m, M \in[a, b]$ and for each $i \in\{1,2,3\}$, one defines

$$
\begin{gathered}
M_{i}(m, M)= \begin{cases}M, & \text { if } F \text { is increasing in } z_{i}, \\
m, & \text { if } F \text { is decreasing in } z_{i},\end{cases} \\
m_{i}(m, M)=M_{i}(M, m)
\end{gathered}
$$

and assume that if $(m, M)$ is a solution of the system

$$
\begin{aligned}
M & =F\left(M_{1}(m, M), M_{2}(m, M), M_{3}(m, M)\right), \\
m & =F\left(m_{1}(m, M), m_{2}(m, M), m_{3}(m, M)\right),
\end{aligned}
$$

then $M=m$.

Then there exists exactly one equilibrium $\bar{x}$ of the equation

$$
x_{n+1}=F\left(x_{n}, x_{n-1}, x_{n-2}\right), \quad n=0,1, \ldots
$$

and every solution of the above equation converges to $\bar{x}$.

The above result in Theorem 1 attracted considerable attention of the leading specialists in difference equations and discrete dynamic systems and has been generalized and extended to the case of maps in $\mathbb{R}^{n}$, see [3], and maps in Banach space with cone, see [4-6].

Moreover, there has been recent interest in establishing fixed-point theorems in partially ordered complete metric spaces with a contractivity condition which holds for all points that are related by partial ordering, (see, e.g., [719]). These fixed-point results have been applied mainly to the existence of solutions of boundary value problems 
for differential equations, namely [18], has been applied for solving a class of matrix equations.

In [20], Burgic et al. obtained the following global attractivity result for mixed monotone mappings in partially ordered complete metric spaces (see also Gnana Bhaskar and Lakshmikantham [10]).

Theorem 2 (see Burgić et al. [20]). Let $(X, \preceq)$ be a partially ordered set and suppose there is a metric $d$ on $X$ such that $(X, d)$ is a complete metric space. Let $F: X \times X \rightarrow X$ be a map such that $F(x, y)$ is nonincreasing in $x$ for all $y \in X$ and nondecreasing in $y$ for all $x \in X$. Suppose that the following conditions hold.

(i) There exists $k \in[0,1)$ with

$$
\begin{aligned}
& d(F(x, y), F(u, v)) \\
& \quad \leq \frac{k}{2}[d(x, u)+d(y, v)] \quad \forall x \preceq u, y \geq v .
\end{aligned}
$$

(ii) There exists $x_{0}, y_{0} \in X$ such that the following condition holds:

$$
x_{0} \preceq F\left(x_{0}, y_{0}\right), \quad y_{0} \succeq F\left(y_{0}, x_{0}\right) .
$$

(iii) If $\left\{x_{n}\right\} \subset X$ is a nondecreasing convergent sequence such that $\lim _{n \rightarrow \infty} x_{n}=x$, then $x_{n} \preceq x$, for all $n \in \mathbb{N}$ and if $\left\{y_{n}\right\} \subset X$ is a nonincreasing convergent sequence such that $\lim _{n \rightarrow \infty} y_{n}=y$, then $y_{n} \geq y$, for all $n \in \mathbb{N}$; if $x_{n} \preceq y_{n}$ for every $n$, then $\lim _{n \rightarrow \infty} x_{n} \preceq \lim _{n \rightarrow \infty} y_{n}$.

Then one has the following.

(a) For every initial point $x_{0}, y_{0} \in X$ such that condition (ii) holds, $F^{n}\left(x_{0}, y_{0}\right) \rightarrow x, F^{n}\left(y_{0}, x_{0}\right) \rightarrow y, n \rightarrow \infty$, where $x, y \in X$ satisfy

$$
x=F(x, y), \quad y=F(y, x) .
$$

(b) If $x_{0} \preceq y_{0}$ in condition (ii), then $x=y$. If in addition $x=y$, then $\left\{x_{n}\right\},\left\{y_{n}\right\}$ converge to the equilibrium of the equation

$$
x_{n+1}=F\left(x_{n}, y_{n}\right), \quad y_{n+1}=F\left(y_{n}, x_{n}\right), \quad n=1,2, \ldots
$$

(c) In particular, every solution $\left\{z_{n}\right\}$ of

$$
z_{n+1}=F\left(z_{n}, z_{n-1}\right), \quad n=2,3, \ldots
$$
(7).

such that $x_{0} \preceq z_{0}, z_{1} \preceq y_{0}$ converges to the equilibrium of

In this paper, motivated by the results and ideas in a recent work of Berinde and Borcut [9], we extend Theorem 2 to mappings $F: X \times X \times X \rightarrow X$. Such extension allows us to study the third-order difference equation

$$
u_{n+1}=F\left(u_{n}, u_{n-1}, u_{n-2}\right), \quad n=2,3, \ldots
$$

The presented theorems also extend and generalize the work in [9]. We use our obtained results to build some iterative algorithms to solve a class of matrix equations. A numerical example is also presented to test the validity of the algorithms.

Now we introduce the following concepts.
Definition 3. Let $X$ be a nonempty set and $F: X \times X \times X \rightarrow$ $X$ a given mapping. One says that $(x, y, z) \in X \times X \times X$ is a fixed-point of the third order if

$$
F(x, y, x)=x, \quad F(y, x, y)=y, \quad F(z, y, z)=z .
$$

Definition 4 . Let $(X, \preceq)$ be a partially ordered set and $F: X \times$ $X \times X \rightarrow X$ a given mapping. one says that $F$ has the mixed monotone property if $F(x, y, z)$ is monotonously increasing in $x$ and $z$ and is monotonously decreasing in $y$; that is, for any $x, y, z \in X$,

(i) $x_{1}, x_{2} \in X, x_{1} \preceq x_{2} \Rightarrow F\left(x_{1}, y, z\right) \preceq F\left(x_{2}, y, z\right)$,

(ii) $y_{1}, y_{2} \in X, y_{1} \preceq y_{2} \Rightarrow F\left(x, y_{1}, z\right) \geq F\left(x, y_{2}, z\right)$, and

(iii) $z_{1}, z_{2} \in X, z_{1} \preceq z_{2} \Rightarrow F\left(x, y, z_{1}\right) \preceq F\left(x, y, z_{2}\right)$.

Through this paper we will use the following notations. Let $(X, \preceq)$ be a partially ordered set.

(i) For $x, y, z \in X \times X \times X$ the notation $x \in[y, z]$ means that $x \geq y$ and $x \preceq z$.

(ii) We endow $X \times X \times X$ with the partial order that we denote also by $\preceq$, defined by

$$
\begin{gathered}
(x, y, z),(u, v, w) \in X \times X \times X, \\
(x, y, z) \preceq(u, v, w) \Longleftrightarrow x \preceq u, y \succeq v, z \preceq w .
\end{gathered}
$$

(iii) Let $F: X \times X \times X \rightarrow X$ be a given mapping. For all $x, y, z \in X$, we denote

$$
\begin{array}{r}
F^{2}(x, y, z)=F(F(x, y, x), F(y, x, y), F(z, y, z)), \\
F^{p+1}(x, y, z)=F\left(F^{p}(x, y, x), F^{p}(y, x, y), F^{p}(z, y, z)\right), \\
\forall p \geq 2 .
\end{array}
$$

\section{Main Result}

Our first result is the following.

Theorem 5. Let $(X, \preceq)$ be a partially ordered set and suppose there is a metric $d$ on $X$ such that $(X, d)$ is a complete metric space. Let $F: X \times X \times X \rightarrow X$ be a mapping having the mixed monotone property on $X$. Suppose that the following conditions hold.

(i) There exists $\lambda \in[0,1)$ with

$$
\begin{aligned}
d(F(x, y, z), F(u, v, w)) \\
\leq \lambda \max \{d(x, u), d(y, v), d(z, w), d(F(x, y, x), x), \\
d(F(x, y, x), u), d(F(y, x, y), y), \\
d(F(y, x, y), v), d(F(z, y, z), z), \\
d(F(z, y, z), w)\}
\end{aligned}
$$

for all $(x, y, z) \preceq(u, v, w)$. 
(ii) There exist $x_{0}, y_{0}, z_{0} \in X$ such that

$$
\begin{gathered}
x_{0} \preceq F\left(x_{0}, y_{0}, x_{0}\right), \quad y_{0} \succeq F\left(y_{0}, x_{0}, y_{0}\right), \\
z_{0} \preceq F\left(z_{0}, y_{0}, z_{0}\right) .
\end{gathered}
$$

(iii) If $\left\{x_{n}\right\} \subset X$ is a nondecreasing convergent sequence such that $\lim _{n \rightarrow \infty} x_{n}=x$, then $x_{n} \preceq x$ for all $n \in \mathbb{N}$, if $\left\{y_{n}\right\} \subset X$ is a nonincreasing convergent sequence such that $\lim _{n \rightarrow \infty} y_{n}=y$, then $y_{n} \geq y$ for every $n \in \mathbb{N}$, and if $x_{n} \preceq y_{n}$ for every $n$, then $\lim _{n \rightarrow \infty} x_{n} \preceq \lim _{n \rightarrow \infty} y_{n}$.

Then one has the following.

(a) For every initial point $\left(x_{0}, y_{0}, z_{0}\right) \in X \times X \times X$ such that condition (14) holds:

$$
\begin{gathered}
x_{n}=F^{n}\left(x_{0}, y_{0}, x_{0}\right) \longrightarrow x, \quad y_{n}=F^{n}\left(y_{0}, x_{0}, y_{0}\right) \longrightarrow y, \\
z_{n}=F^{n}\left(z_{0}, y_{0}, z_{0}\right) \longrightarrow z \text { as } n \rightarrow \infty,
\end{gathered}
$$

where $x, y$, and $z$ satisfy

$$
x=F(x, y, x), \quad y=F(y, x, y), \quad z=F(z, y, z) \text {. }
$$

If $x_{0} \preceq y_{0}$ and $z_{0} \preceq y_{0}$ in condition (14), then $x=y=$ $z$ and $\left\{x_{n}\right\},\left\{y_{n}\right\}$, and $\left\{z_{n}\right\}$ converge to the equilibrium of the equation

$$
\begin{gathered}
x_{n+1}=F\left(x_{n}, y_{n}, x_{n}\right), \quad y_{n+1}=F\left(y_{n}, x_{n}, y_{n}\right), \\
z_{n+1}=F\left(z_{n}, y_{n}, z_{n}\right), \quad n=0,1,2 \ldots
\end{gathered}
$$

(b) In particular, every solution $\left\{u_{n}\right\}$ of

$$
u_{n+1}=F\left(u_{n}, u_{n-1}, u_{n-2}\right), \quad n=2,3, \ldots,
$$

such that $u_{0}, u_{1}, u_{2} \in\left[x_{0}, y_{0}\right]$ (or $\left.\left[z_{0}, y_{0}\right]\right)$ converges to the equilibrium of (18).

(c) The following estimates hold:

$$
\begin{array}{r}
d\left(x, F^{n}\left(x_{0}, y_{0}, x_{0}\right)\right) \\
\leq \frac{\lambda^{n}}{1-\lambda} \max \left\{d\left(F\left(x_{0}, y_{0}, x_{0}\right), x_{0}\right),\right. \\
d\left(F\left(y_{0}, x_{0}, y_{0}\right), y_{0}\right), \\
\left.d\left(z_{0}, F\left(z_{0}, y_{0}, z_{0}\right)\right)\right\},
\end{array}
$$

$$
\begin{array}{r}
d\left(y, F^{n}\left(y_{0}, x_{0}, y_{0}\right)\right) \\
\leq \frac{\lambda^{n}}{1-\lambda} \max \left\{d\left(F\left(x_{0}, y_{0}, x_{0}\right), x_{0}\right),\right. \\
d\left(F\left(y_{0}, x_{0}, y_{0}\right), y_{0}\right), \\
\left.d\left(z_{0}, F\left(z_{0}, y_{0}, z_{0}\right)\right)\right\}, \\
d\left(z, F^{n}\left(z_{0}, y_{0}, z_{0}\right)\right) \\
\leq \frac{\lambda^{n}}{1-\lambda} \max \left\{d\left(F\left(x_{0}, y_{0}, x_{0}\right), x_{0}\right),\right. \\
d\left(F\left(y_{0}, x_{0}, y_{0}\right), y_{0}\right), \\
\left.d\left(F\left(z_{0}, y_{0}, z_{0}\right), z_{0}\right)\right\} .
\end{array}
$$

Proof. Let $x_{0}, y_{0}, z_{0} \in X$ such that condition (14) is satisfied. Denote $x_{1}=F\left(x_{0}, y_{0}, x_{0}\right), y_{1}=F\left(y_{0}, x_{0}, y_{0}\right)$, and $z_{1}=$ $F\left(z_{0}, y_{0}, z_{0}\right)$. Since $x_{0} \preceq F\left(x_{0}, y_{0}, x_{0}\right)=x_{1}, y_{0} \succeq$ $F\left(y_{0}, x_{0}, y_{0}\right)=y_{1}$, and $z_{0} \preceq F\left(z_{0}, y_{0}, z_{0}\right)=y_{1}$, from the mixed monotone property of $F$, we get that

$$
\begin{aligned}
& x_{0} \preceq x_{1}=F\left(x_{0}, y_{0}, x_{0}\right) \preceq x_{2}=F\left(x_{1}, y_{1}, x_{1}\right), \\
& y_{0} \succeq y_{1}=F\left(y_{0}, x_{0}, y_{0}\right) \succeq y_{2}=F\left(y_{1}, x_{1}, y_{1}\right), \\
& z_{0} \preceq z_{1}=F\left(z_{0}, y_{0}, z_{0}\right) \preceq z_{2}=F\left(z_{1}, y_{1}, z_{1}\right) .
\end{aligned}
$$

Consider the sequences $\left\{x_{n}\right\},\left\{y_{n}\right\}$, and $\left\{z_{n}\right\}$ defined by (17). By induction and using the mixed monotone property of $F$, we obtain easily that

$$
\begin{gathered}
x_{0} \preceq x_{1} \preceq \cdots \preceq x_{n} \preceq \cdots ; \quad y_{0} \succeq y_{1} \succeq \cdots \succeq y_{n} \succeq \cdots ; \\
z_{0} \preceq z_{1} \preceq \cdots \preceq z_{n} \preceq \cdots
\end{gathered}
$$

For the sake of clarity, for all $n \geq 1$, denote

$$
\begin{gathered}
D_{n}^{x}=d\left(x_{n-1}, x_{n}\right), \quad D_{n}^{y}=d\left(y_{n-1}, y_{n}\right), \\
D_{n}^{z}=d\left(z_{n-1}, z_{n}\right) .
\end{gathered}
$$

We claim that, for all $n \geq 1$, we have

$$
\begin{aligned}
& D_{n+1}^{x} \leq \lambda^{n} \max \left\{D_{1}^{x}, D_{1}^{y}, D_{1}^{z}\right\}, \\
& D_{n+1}^{y} \leq \lambda^{n} \max \left\{D_{1}^{x}, D_{1}^{y}, D_{1}^{z}\right\}, \\
& D_{n+1}^{z} \leq \lambda^{n} \max \left\{D_{1}^{x}, D_{1}^{y}, D_{1}^{z}\right\} .
\end{aligned}
$$


By (13) and (21), we obtain

$$
\begin{aligned}
& D_{2}^{x}=d\left(x_{1}, x_{2}\right)=d\left(F\left(x_{0}, y_{0}, x_{0}\right), F\left(x_{1}, y_{1}, x_{1}\right)\right) \\
& \leq \lambda \max \left\{d\left(x_{0}, x_{1}\right), d\left(y_{0}, y_{1}\right), d\left(x_{0}, x_{1}\right),\right. \\
& d\left(F\left(x_{0}, y_{0}, x_{0}\right), x_{0}\right), d\left(F\left(x_{0}, y_{0}, x_{0}\right), x_{1}\right), \\
& d\left(F\left(y_{0}, x_{0}, y_{0}\right), y_{0}\right), d\left(F\left(y_{0}, x_{0}, y_{0}\right), y_{1}\right), \\
& \left.d\left(F\left(x_{0}, y_{0}, x_{0}\right), x_{0}\right), d\left(F\left(x_{0}, y_{0}, x_{0}\right), x_{1}\right)\right\} \\
& =\lambda \max \left\{d\left(x_{0}, x_{1}\right), d\left(y_{0}, y_{1}\right)\right\}, \\
& D_{2}^{y}=d\left(y_{1}, y_{2}\right)=d\left(F\left(y_{0}, x_{0}, y_{0}\right), F\left(y_{1}, x_{1}, y_{1}\right)\right) \\
& \leq \lambda \max \left\{d\left(y_{0}, y_{1}\right), d\left(x_{0}, x_{1}\right), d\left(y_{0}, y_{1}\right),\right. \\
& d\left(F\left(y_{0}, x_{0}, y_{0}\right), y_{0}\right), d\left(F\left(y_{0}, x_{0}, y_{0}\right), y_{1}\right), \\
& d\left(F\left(x_{0}, y_{0}, x_{0}\right), x_{0}\right), d\left(F\left(x_{0}, y_{0}, x_{0}\right), x_{1}\right), \\
& \left.d\left(F\left(y_{0}, x_{0}, y_{0}\right), y_{0}\right), d\left(F\left(y_{0}, x_{0}, y_{0}\right), y_{1}\right)\right\} \\
& =\lambda \max \left\{d\left(y_{0}, y_{1}\right), d\left(x_{0}, x_{1}\right)\right\}, \\
& D_{2}^{z}=d\left(z_{1}, z_{2}\right)=d\left(F\left(z_{0}, y_{0}, z_{0}\right), F\left(z_{1}, y_{1}, z_{1}\right)\right) \\
& \leq \lambda \max \left\{d\left(z_{0}, z_{1}\right), d\left(y_{0}, y_{1}\right), d\left(z_{0}, z_{1}\right),\right. \\
& d\left(F\left(z_{0}, y_{0}, z_{0}\right), z_{0}\right), d\left(F\left(z_{0}, y_{0}, z_{0}\right), z_{1}\right), \\
& d\left(F\left(y_{0}, z_{0}, y_{0}\right), y_{0}\right), d\left(F\left(y_{0}, z_{0}, y_{0}\right), y_{1}\right), \\
& \left.d\left(F\left(z_{0}, y_{0}, z_{0}\right), z_{0}\right), d\left(F\left(z_{0}, y_{0}, z_{0}\right), z_{1}\right)\right\} \\
& =\lambda \max \left\{d\left(z_{0}, z_{1}\right), d\left(y_{0}, y_{1}\right)\right\} \text {. }
\end{aligned}
$$

Thus we get that

$$
\begin{gathered}
D_{2}^{x} \leq \lambda \max \left\{D_{1}^{x}, D_{1}^{y}, D_{1}^{z}\right\}, \quad D_{2}^{y} \leq \lambda \max \left\{D_{1}^{x}, D_{1}^{y}, D_{1}^{z}\right\}, \\
D_{2}^{z} \leq \lambda \max \left\{D_{1}^{x}, D_{1}^{y}, D_{1}^{z}\right\} .
\end{gathered}
$$

Then our claim holds for $n=1$. Suppose now that (23) holds for some fixed $n \geq 1$. Similarly, by (13) and (21), we obtain

$$
\begin{aligned}
D_{n+2}^{x} & =d\left(x_{n+1}, x_{n+2}\right) \\
& =d\left(F\left(x_{n}, y_{n}, x_{n}\right), F\left(x_{n+1}, y_{n+1}, x_{n+1}\right)\right) \\
& \leq \lambda \max \left\{D_{n+1}^{x}, D_{n+1}^{y}\right\} \\
& \leq \lambda^{n+1} \max \left\{D_{1}^{x}, D_{1}^{y}, D_{1}^{y}\right\} .
\end{aligned}
$$

Similarly, one can show that

$$
\begin{aligned}
& D_{n+2}^{y} \leq \lambda^{n+1} \max \left\{D_{1}^{x}, D_{1}^{y}, D_{1}^{z}\right\}, \\
& D_{n+2}^{z} \leq \lambda^{n+1} \max \left\{D_{1}^{x}, D_{1}^{y}, D_{1}^{z}\right\} .
\end{aligned}
$$

Then by the induction principle, (23) holds for all $n \geq 1$.
Now we will prove that $\left\{x_{n}\right\},\left\{y_{n}\right\}$, and $\left\{z_{n}\right\}$ are Cauchy sequences in the metric space $(X, d)$. Using (23) and the triangular inequality, for $m>n$, we have

$$
\begin{aligned}
d\left(x_{m}, x_{n}\right) & \leq \sum_{i=n}^{m-1} d\left(x_{i}, x_{i+1}\right)=\sum_{i=n}^{m-1} D_{i+1}^{x} \\
& \leq \sum_{i=n}^{m-1} \lambda^{i} \max \left\{D_{1}^{x}, D_{1}^{y}, D_{1}^{z}\right\} \\
& \leq\left(\sum_{i=n}^{m-1} \lambda^{i}\right) \max \left\{D_{1}^{x}, D_{1}^{y}, D_{1}^{z}\right\} \\
& \leq \frac{\lambda^{n}}{1-\lambda} \max \left\{D_{1}^{x}, D_{1}^{y}, D_{1}^{z}\right\} \rightarrow 0 \text { as } n \rightarrow \infty .
\end{aligned}
$$

This implies that $\left\{x_{n}\right\}$ is a Cauchy sequence. Similarly, one can prove that $\left\{y_{n}\right\}$ and $\left\{z_{n}\right\}$ are Cauchy sequences.

Since $(X, d)$ is complete, there exist $x, y, z \in X$ such that

$$
\begin{aligned}
& x_{n} \longrightarrow x, \quad y_{n} \longrightarrow y, \\
& z_{n} \longrightarrow z \quad \text { as } n \longrightarrow \infty .
\end{aligned}
$$

From condition (iii) and (21), we get that

$$
x_{n} \preceq x, \quad y_{n} \geq y, \quad z_{n} \preceq z, \quad \forall n .
$$

We claim that $x=F(x, y, x)$. Indeed, we have

$$
\begin{aligned}
& d(x, F(x, y, x)) \\
& \leq d\left(x, x_{n+1}\right)+d\left(x_{n+1}, F(x, y, x)\right) \\
& =d\left(x, x_{n+1}\right)+d\left(F\left(x_{n}, y_{n}, x_{n}\right), F(x, y, x)\right) \\
& \leq d\left(x, x_{n+1}\right) \\
& \quad+\lambda \max \left\{d\left(x_{n}, x\right), d\left(y_{n}, y\right),\right. \\
& \quad d\left(x_{n}, x\right), d\left(F\left(x_{n}, y_{n}, x_{n}\right), x_{n}\right), \\
& \quad d\left(F\left(x_{n}, y_{n}, x_{n}\right), x\right), d\left(F\left(y_{n}, x_{n}, y_{n}\right), y_{n}\right), \\
& \quad d\left(F\left(y_{n}, x_{n}, y_{n}\right), y\right), d\left(F\left(x_{n}, y_{n}, x_{n}\right), x_{n}\right), \\
& \left.\quad d\left(F\left(x_{n}, y_{n}, x_{n}\right), x\right)\right\} \\
& =d\left(x, x_{n+1}\right)+\lambda \max \left\{d\left(x_{n}, x\right), d\left(y_{n}, y\right)\right\} \\
& \quad \text { as } n \longrightarrow \infty \quad \text { by }(29) .
\end{aligned}
$$

Then, our claim holds; that is, $x=F(x, y, x)$. Similarly, one can show that $y=F(y, x, y)$ and $z=F(z, y, z)$. Thus we proved (16).

On the other hand, from (28), for $m>n$ with $n$ being fixed, we have

$$
\begin{aligned}
d\left(x_{m}, x_{n}\right) & =d\left(x_{m}, F^{n}\left(x_{0}, y_{0}, x_{0}\right)\right) \\
& \leq \frac{\lambda^{n}}{1-\lambda} \max \left\{D_{1}^{x}, D_{1}^{y}, D_{1}^{z}\right\}
\end{aligned}
$$


Letting $m \rightarrow \infty$ in the above inequality, we obtain

$$
\begin{aligned}
& d\left(x, F^{n}\left(x_{0}, y_{0}, x_{0}\right)\right) \\
& \quad \leq \frac{\lambda^{n}}{1-\lambda} \max \left\{d\left(x_{0}, x_{1}\right), d\left(y_{0}, y_{1}\right), d\left(z_{0}, z_{1}\right)\right\}
\end{aligned}
$$

that is,

$$
\begin{array}{r}
d\left(x, F^{n}\left(x_{0}, y_{0}, x_{0}\right)\right) \\
\leq \frac{\lambda^{n}}{1-\lambda} \max \left\{d\left(x_{0}, F\left(x_{0}, y_{0}, x_{0}\right)\right),\right. \\
d\left(y_{0}, F\left(y_{0}, x_{0}, y_{0}\right)\right), \\
\left.d\left(z_{0}, F\left(z_{0}, y_{0}, z_{0}\right)\right)\right\} .
\end{array}
$$

Similarly, one can show that

$$
\begin{array}{r}
d\left(y, F^{n}\left(y_{0}, x_{0}, y_{0}\right)\right) \\
\leq \frac{\lambda^{n}}{1-\lambda} \max \left\{d\left(x_{0}, F\left(x_{0}, y_{0}, x_{0}\right)\right),\right. \\
d\left(y_{0}, F\left(y_{0}, x_{0}, y_{0}\right)\right), \\
\left.d\left(z_{0}, F\left(z_{0}, y_{0}, z_{0}\right)\right)\right\}, \\
d\left(z, F^{n}\left(z_{0}, y_{0}, z_{0}\right)\right) \\
\leq \frac{\lambda^{n}}{1-\lambda} \max \left\{d\left(x_{0}, F\left(x_{0}, y_{0}, x_{0}\right)\right),\right. \\
d\left(y_{0}, F\left(y_{0}, x_{0}, y_{0}\right)\right), \\
\left.d\left(z_{0}, F\left(z_{0}, y_{0}, z_{0}\right)\right)\right\} .
\end{array}
$$

Thus we proved (19).

Now, if $x_{0} \preceq y_{0}$ and $z_{0} \preceq y_{0}$, we claim that, for all $n \in$ $\mathbb{N}, x_{n} \preceq y_{n}$ and $z_{n} \preceq y_{n}$. Indeed, by the mixed monotone property of $F$,

$$
\begin{aligned}
& x_{1}=F\left(x_{0}, y_{0}, x_{0}\right) \preceq F\left(y_{0}, x_{0}, y_{0}\right)=y_{1}, \\
& z_{1}=F\left(z_{0}, y_{0}, z_{0}\right) \preceq F\left(y_{0}, x_{0}, y_{0}\right)=y_{1} .
\end{aligned}
$$

Assume that $x_{n} \preceq y_{n}$ and $z_{n} \preceq y_{n}$ for some $n$. Then,

$$
x_{n+1}=F\left(x_{n}, y_{n}, x_{n}\right) \preceq F\left(y_{n}, x_{n}, y_{n}\right)=y_{n+1},
$$

and similarly for $y_{n}$ and $z_{n}$. Thus we proved that

$$
x_{n} \preceq y_{n}, \quad z_{n} \preceq y_{n}, \quad \forall n \in \mathbb{N} .
$$

Next, from (38), we have

$$
\begin{aligned}
d(x, y) \leq & d\left(x, x_{n+1}\right)+d\left(x_{n+1}, y_{n+1}\right)+d\left(y_{n+1}, y\right) \\
\leq & d\left(x, x_{n+1}\right)+d\left(F\left(x_{n}, y_{n}, x_{n}\right), F\left(y_{n}, x_{n}, y_{n}\right)\right) \\
& +d\left(y_{n+1}, y\right) \\
\leq & d\left(x, x_{n+1}\right)+\lambda d\left(x_{n}, z_{n}\right)+d\left(y_{n+1}, y\right)
\end{aligned}
$$

$$
\begin{aligned}
& \leq d\left(x, x_{n+1}\right)+\lambda^{n} d\left(x_{0}, y_{0}\right)+d\left(y_{n+1}, y\right) \\
& \longrightarrow 0 \quad \text { as } n \longrightarrow \infty,
\end{aligned}
$$

which implies that $x=y$. Similarly, we obtain that $d(y, z)=$ 0 , that is, $y=z$. Then $x=y=z$.

Now, assume that $x_{0} \preceq y_{0}$. Then, in view of the monotonicity of $F$, we have

$$
\begin{aligned}
x_{1} & =F\left(x_{0}, y_{0}, x_{0}\right) \preceq x_{2}=F\left(x_{1}, y_{1}, x_{1}\right) \\
& \preceq F\left(y_{1}, x_{1}, y_{1}\right)=y_{2} \preceq F\left(y_{0}, x_{0}, y_{0}\right)=y_{1} .
\end{aligned}
$$

Continuing this process, one can show that

$$
x_{n} \preceq x_{n+1} \preceq y_{n+1} \preceq y_{n}, \quad \forall n .
$$

If we assume that $u_{0}, u_{1}, u_{2} \in\left[x_{0}, y_{0}\right]$, in view of the monotonicity of $F$, we have

$$
\begin{aligned}
x_{1} & =F\left(x_{0}, y_{0}, x_{0}\right) \preceq F\left(u_{2}, u_{1}, u_{0}\right) \\
& =u_{3} \preceq F\left(y_{0}, x_{0}, y_{0}\right)=y_{1}, \\
x_{1} & =F\left(x_{0}, y_{0}, x_{0}\right) \preceq F\left(u_{3}, u_{2}, u_{1}\right) \\
& =u_{4} \preceq F\left(y_{0}, x_{0}, y_{0}\right)=y_{1}, \\
x_{1} & =F\left(x_{0}, y_{0}, x_{0}\right) \preceq F\left(u_{4}, u_{3}, u_{2}\right) \\
& =u_{5} \preceq F\left(y_{0}, x_{0}, y_{0}\right)=y_{1} .
\end{aligned}
$$

Continuing in a similar way, we can prove that

$$
x_{k} \preceq u_{3 k}, u_{3 k+1}, u_{3 k+2} \preceq y_{k}, \quad \forall k \geq 1 .
$$

Letting $k \rightarrow \infty$ and using (iii) and (29), we get that $u_{n} \rightarrow x$ as $n \rightarrow \infty$, where $x$ is the equilibrium of (17). Similarly, if $z_{0} \preceq y_{0}$ and $u_{0}, u_{1}, u_{2} \in\left[z_{0}, y_{0}\right]$, we obtain also the same result.

Remark 6. If we replace the condition, if $\left\{x_{n}\right\} \subset X$ is a nondecreasing convergent sequence such that $\lim _{n \rightarrow \infty} x_{n}=$ $x$, then $x_{n} \preceq x$ for all $n \in \mathbb{N}$ and if $\left\{y_{n}\right\} \subset X$ is a nonincreasing convergent sequence such that $\lim _{n \rightarrow \infty} y_{n}=y$, then $y_{n} \geq y$ for every $n \in \mathbb{N}$, by the continuity of $F$, we can check easily that the result of Theorem 5 holds also in this case.

Theorem 7. In addition to the hypotheses of Theorem 5, suppose that for every $(x, y, z),\left(x^{\prime}, y^{\prime}, z^{\prime}\right) \in X \times X \times X$, there 
exists $(u, v, w)$ such that $(x, y, z) \preceq(u, v, w)$ and $\left(x^{\prime}, y^{\prime}, z^{\prime}\right) \preceq$ $(u, v, w)$. Then one obtains the uniqueness of the fixed point of the third order.

Proof. From (a) of Theorem 5, we know that $F$ admits a fixed point of the third order $(x, y, z) \in X \times X \times X$; that is,

$$
x=F(x, y, x), \quad y=F(y, x, y), \quad z=F(z, y, z),
$$

where

$$
\begin{gathered}
x_{n}=F^{n}\left(x_{0}, y_{0}, x_{0}\right) \longrightarrow x, \quad y_{n}=F^{n}\left(y_{0}, x_{0}, y_{0}\right) \longrightarrow y, \\
z_{n}=F^{n}\left(z_{0}, y_{0}, z_{0}\right) \longrightarrow z \quad \text { as } n \longrightarrow \infty .
\end{gathered}
$$

Suppose that $\left(x^{*}, y^{*}, z^{*}\right) \in X \times X \times X$ is another fixed point of the third order of $F$; that is,

$$
\begin{gathered}
x^{*}=F\left(x^{*}, y^{*}, x^{*}\right), \quad y^{*}=F\left(y^{*}, x^{*}, y^{*}\right), \\
z^{*}=F\left(z^{*}, y^{*}, z^{*}\right) .
\end{gathered}
$$

We will prove that

$$
\eta\left((x, y, z),\left(x^{*}, y^{*}, z^{*}\right)\right)=0,
$$

where

$$
\begin{aligned}
& \eta\left((x, y, z),\left(x^{*}, y^{*}, z^{*}\right)\right) \\
& \quad=\max \left\{d\left(x, x^{*}\right), d\left(y, y^{*}\right), d\left(z, z^{*}\right)\right\} .
\end{aligned}
$$

From the hypothesis of Theorem 7 , there exists $(u, v, w)$ such that

$$
(x, y, z) \preceq(u, v, w), \quad\left(x^{*}, y^{*}, z^{*}\right) \preceq(u, v, w) .
$$

Since $F$ is a mixed monotone operator, we have

$$
\begin{gathered}
\left(F^{n}(x, y, x), F^{n}(y, x, y), F^{n}(z, y, z)\right) \\
=(x, y, z) \leq\left(F^{n}(u, v, w), F^{n}(v, u, v), F^{n}(w, v, w)\right), \\
\left(F^{n}\left(x^{*}, y^{*}, x^{*}\right), F^{n}\left(y^{*}, x^{*}, y^{*}\right), F^{n}\left(z^{*}, y^{*}, z^{*}\right)\right) \\
=\left(x^{*}, y^{*}, z^{*}\right) \leq\left(F^{n}(u, v, w), F^{n}(v, u, v),\right. \\
\left.F^{n}(w, v, w)\right) .
\end{gathered}
$$

We have

$$
\begin{gathered}
\eta\left((x, y, z),\left(x^{*}, y^{*}, z^{*}\right)\right) \\
=\eta\left(\left(F^{n}(x, y, x), F^{n}(y, x, y), F^{n}(z, y, z)\right),\right. \\
\left(F^{n}\left(x^{*}, y^{*}, x^{*}\right), F^{n}\left(y^{*}, x^{*}, y^{*}\right),\right. \\
\left.\left.F^{n}\left(z^{*}, y^{*}, z^{*}\right)\right)\right) \\
\leq \eta\left(\left(F^{n}(x, y, x), F^{n}(y, x, y), F^{n}(z, y, z)\right),\right. \\
\left.\left(F^{n}(u, v, u), F^{n}(v, u, v), F^{n}(w, v, w)\right)\right) \\
+\eta\left(\left(F^{n}(u, v, u), F^{n}(v, u, v), F^{n}(w, v, w)\right),\right. \\
\left(F^{n}\left(x^{*}, y^{*}, x^{*}\right), F^{n}\left(y^{*}, x^{*}, y^{*}\right),\right. \\
\left.\left.F^{n}\left(z^{*}, y^{*}, z^{*}\right)\right)\right) \\
\leq \lambda^{n} \max \{d(x, u), d(y, v), d(z, w)\} \\
+\lambda^{n} \max \left\{d\left(u, x^{*}\right), d\left(v, y^{*}\right), d\left(w, z^{*}\right)\right\} \\
\longrightarrow 0 \quad \operatorname{as} n \rightarrow \infty,
\end{gathered}
$$

which implies that

$$
\eta\left((x, y, z),\left(x^{*}, y^{*}, z^{*}\right)\right)=0
$$

that is,

$$
x=x^{*}, \quad y=y^{*}, \quad z=z^{*} .
$$

Example 8. Let $X=[0,1]$ be an ordered set with the natural ordering of real numbers and $d$ a usual metric on $X$. Let $F$ : $X \times X \times X \rightarrow X$ be defined by

$$
F(x, y, z)=\frac{1+x-y+2 z}{8} \quad \forall x, y, z \in X .
$$

It is easy to check that $F$ has the mixed monotone property on $X$. For $x, y, z, u, v, w \in X$ with $(x, y, z) \leq(u, v, w)$, we have

$$
\begin{aligned}
d(F(x, y, z), F(u, v, w)) & \\
= & \frac{1}{8}|x-u-(y-v)+2(z-w)| \\
\leq & \frac{1}{8}[|x-u|+|y-v|+2|z-w|] \\
\leq & \frac{3}{4} \max \{|x-u|,|y-v|,|z-w|\} \\
= & \frac{3}{4} \max \{d(x, u), d(y, v), d(z, w)\} \\
\leq & \frac{3}{4} \max \{d(x, u), d(y, v), d(z, w), \\
& \quad d(F(x, y, x), x), d(F(x, y, x), u), \\
& \quad d(F(y, x, y), y), d(F(y, x, y), v), \\
& \quad d(F(z, y, z), z), d(F(z, y, z), w)\} .
\end{aligned}
$$


Thus (13) is satisfied for $\lambda=3 / 4 \in[0,1)$. Thus all the conditions of Theorems 5 and 7 are satisfied. Moreover, there exists a unique $(x, y, z)=(1 / 6,1 / 6,1 / 6)$ in $X \times X \times X$ such that

$$
F(x, y, x)=x, \quad F(y, x, y)=y, \quad F(z, y, z)=z .
$$

Corollary 9. Let $(X, \preceq)$ be a partially ordered set and suppose there is a metric $d$ on $X$ such that $(X, d)$ is a complete metric space. Let $F: X \times X \times X \rightarrow X$ be a mapping having the mixed monotone property on $X$. Suppose that the following conditions hold.

(1) There exists $a_{i \text { 's }} \geq 0$ for $i=1,2, \ldots, 9$ and $\sum_{i=1}^{9} a_{i}<1$ with

$$
\begin{aligned}
& d(F(x, y, z), F(u, v, w)) \\
& \leq a_{1} d(x, u)+a_{2} d(y, v)+a_{3} d(z, w) \\
&+a_{4} d(F(x, y, x), x)+a_{5} d(F(x, y, x), u) \\
&+a_{6} d(F(y, x, y), y)+a_{7} d(F(y, x, y), v) \\
&+a_{8} d(F(z, y, z), z)+a_{9} d(F(z, y, z), w)
\end{aligned}
$$

for all $(x, y, z) \preceq(u, v, w)$.

(2) There exist $x_{0}, y_{0}, z_{0} \in X$ such that

$$
\begin{gathered}
x_{0} \preceq F\left(x_{0}, y_{0}, x_{0}\right), \quad y_{0} \succeq F\left(y_{0}, x_{0}, y_{0}\right), \\
z_{0} \preceq F\left(z_{0}, y_{0}, z_{0}\right) .
\end{gathered}
$$

(3) If $\left\{x_{n}\right\} \subset X$ is a nondecreasing convergent sequence such that $\lim _{n \rightarrow \infty} x_{n}=x$, then $x_{n} \preceq x$ for all $n \in \mathbb{N}$, if $\left\{y_{n}\right\} \subset X$ is a nonincreasing convergent sequence such that $\lim _{n \rightarrow \infty} y_{n}=y$, then $y_{n} \geq y$ for every $n \in \mathbb{N}$, and if $x_{n} \preceq y_{n}$ for every $n \in \mathbb{N}$, then $\lim _{n \rightarrow \infty} x_{n} \preceq$ $\lim _{n \rightarrow \infty} y_{n}$.

Then one has the following.

(a) For every initial point $\left(x_{0}, y_{0}, z_{0}\right) \in X \times X \times X$ such that condition (14) holds,

$$
\begin{gathered}
x_{n}=F^{n}\left(x_{0}, y_{0}, x_{0}\right) \longrightarrow x, \quad y_{n}=F^{n}\left(y_{0}, x_{0}, y_{0}\right) \longrightarrow y, \\
z_{n}=F^{n}\left(z_{0}, y_{0}, z_{0}\right) \longrightarrow z \text { as } n \longrightarrow \infty,
\end{gathered}
$$

where $x, y$, and $z$ satisfy

$$
x=F(x, y, x), \quad y=F(y, x, y), \quad z=F(z, y, z) \text {. }
$$

If $x_{0} \preceq y_{0}$ and $z_{0} \preceq y_{0}$ in condition (14), then $x=y=$ $z$ and $\left\{x_{n}\right\},\left\{y_{n}\right\}$, and $\left\{z_{n}\right\}$ converge to the equilibrium of the equation

$$
\begin{gathered}
x_{n+1}=F\left(x_{n}, y_{n}, x_{n}\right), \quad y_{n+1}=F\left(y_{n}, x_{n}, y_{n}\right), \\
z_{n+1}=F\left(z_{n}, y_{n}, z_{n}\right), \quad n=0,1,2 \ldots
\end{gathered}
$$

(b) In particular, every solution $\left\{u_{n}\right\}$ of

$$
u_{n+1}=F\left(u_{n}, u_{n-1}, u_{n-2}\right), \quad n=2,3, \ldots
$$

such that $u_{0}, u_{1}, u_{2} \in\left[x_{0}, y_{0}\right]$ (or $\left[z_{0}, y_{0}\right]$ ) converges to the equilibrium of (18).

Proof. Note that (14) implies that

$$
\begin{aligned}
& d(F(x, y, z), F(u, v, w)) \\
& \leq h \max \{ d(x, u), d(y, v), d(z, w), \\
& d(F(x, y, x), x), d(F(x, y, x), u), \\
& d(F(y, x, y), y), d(F(y, x, y), v), \\
&d(F(z, y, z), z), d(F(z, y, z), w)\}
\end{aligned}
$$

for all $(x, y, z) \preceq(u, v, w)$, where $h=\sum_{i=1}^{9} a_{i}<1$ and the result follows from Theorem 5 .

Corollary 10. In addition to the hypotheses of Corollary 9, suppose that for every $(x, y, z),\left(x^{\prime}, y^{\prime}, z^{\prime}\right) \in X \times X \times X$, there exists $(u, v, w)$ such that $(x, y, z) \preceq(u, v, w)$ and $\left(x^{\prime}, y^{\prime}, z^{\prime}\right) \preceq$ $(u, v, w)$. Then one obtains the uniqueness of the fixed point of the third order.

Corollary 11. Let $(X, \preceq)$ be a partially ordered set and suppose there is a metric $d$ on $X$ such that $(X, d)$ is a complete metric space. Let $F: X \times X \times X \rightarrow X$ be a mapping having the mixed monotone property on $X$. Suppose that the following conditions hold.

(1) There exists $\lambda \in[0,1)$ with

$$
\begin{gathered}
d(F(x, y, z), F(u, v, w)) \\
\leq \lambda \max \{d(x, u), d(y, v), d(z, w)\} \\
\forall(x, y, z) \leq(u, v, w) .
\end{gathered}
$$

(2) There exist $x_{0}, y_{0}, z_{0} \in X$ such that

$$
\begin{gathered}
x_{0} \preceq F\left(x_{0}, y_{0}, x_{0}\right), \quad y_{0} \succeq F\left(y_{0}, x_{0}, y_{0}\right), \\
z_{0} \preceq F\left(z_{0}, y_{0}, z_{0}\right) .
\end{gathered}
$$

(3) If $\left\{x_{n}\right\} \subset X$ is a nondecreasing convergent sequence such that $\lim _{n \rightarrow \infty} x_{n}=x$, then $x_{n} \preceq x$ for all $n \in \mathbb{N}$; if $\left\{y_{n}\right\} \subset X$ is a nonincreasing convergent sequence such that $\lim _{n \rightarrow \infty} y_{n}=y$, then $y_{n} \geq y$ for every $n \in \mathbb{N}$, and if $x_{n} \preceq y_{n}$ for every $n$, then $\lim _{n \rightarrow \infty} x_{n} \preceq \lim _{n \rightarrow \infty} y_{n}$.

Then one has the following.

(a) For every initial point $\left(x_{0}, y_{0}, z_{0}\right) \in X \times X \times X$ such that condition (14) holds,

$$
\begin{gathered}
x_{n}=F^{n}\left(x_{0}, y_{0}, x_{0}\right) \longrightarrow x, \quad y_{n}=F^{n}\left(y_{0}, x_{0}, y_{0}\right) \longrightarrow y, \\
z_{n}=F^{n}\left(z_{0}, y_{0}, z_{0}\right) \longrightarrow z \text { as } n \longrightarrow \infty,
\end{gathered}
$$


where $x, y$, and $z$ satisfy

$x=F(x, y, x), \quad y=F(y, x, y), \quad z=F(z, y, z)$.

If $x_{0} \preceq y_{0}$ and $z_{0} \preceq y_{0}$ in condition (14), then $x=y=$ $z$ and $\left\{x_{n}\right\},\left\{y_{n}\right\}$, and $\left\{z_{n}\right\}$ converge to the equilibrium of the equation

$$
\begin{gathered}
x_{n+1}=F\left(x_{n}, y_{n}, x_{n}\right), \quad y_{n+1}=F\left(y_{n}, x_{n}, y_{n}\right), \\
z_{n+1}=F\left(z_{n}, y_{n}, z_{n}\right), \quad n=0,1,2 \ldots
\end{gathered}
$$

(b) In particular, every solution $\left\{u_{n}\right\}$ of

$$
u_{n+1}=F\left(u_{n}, u_{n-1}, u_{n-2}\right), \quad n=2,3, \ldots
$$

such that $u_{0}, u_{1}, u_{2} \in\left[x_{0}, y_{0}\right]$ (or $\left.\left[z_{0}, y_{0}\right]\right)$ converges to the equilibrium of (18).

(c) The following estimates hold:

$$
\begin{array}{r}
d\left(x, F^{n}\left(x_{0}, y_{0}, x_{0}\right)\right) \\
\leq \frac{\lambda^{n}}{1-\lambda} \max \left\{d\left(F\left(x_{0}, y_{0}, x_{0}\right), x_{0}\right),\right. \\
d\left(F\left(y_{0}, x_{0}, y_{0}\right), y_{0}\right), \\
\left.d\left(z_{0}, F\left(z_{0}, y_{0}, z_{0}\right)\right)\right\}, \\
d\left(y, F^{n}\left(y_{0}, x_{0}, y_{0}\right)\right) \\
\leq \frac{\lambda^{n}}{1-\lambda} \max \left\{d\left(F\left(x_{0}, y_{0}, x_{0}\right), x_{0}\right),\right. \\
\left.\left.\left.d\left(z_{0}, F\left(z_{0}, y_{0}\right), y_{0}\right), z_{0}\right)\right)\right\}, \\
d\left(z, F^{n}\left(z_{0}, y_{0}, z_{0}\right)\right) \\
\leq \frac{\lambda^{n}}{1-\lambda} \max \left\{d\left(F\left(x_{0}, y_{0}, x_{0}\right), x_{0}\right),\right. \\
d\left(F\left(y_{0}, x_{0}, y_{0}\right), y_{0}\right), \\
\left.d\left(F\left(z_{0}, y_{0}, z_{0}\right), z_{0}\right)\right\} .
\end{array}
$$

Corollary 12. In addition to the hypotheses of Corollary 11, suppose that for every $(x, y, z),\left(x^{\prime}, y^{\prime}, z^{\prime}\right) \in X \times X \times X$, there exists $(u, v, w)$ such that $(x, y, z) \preceq(u, v, w)$ and $\left(x^{\prime}, y^{\prime}, z^{\prime}\right) \preceq$ $(u, v, w)$. Then one obtains the uniqueness of the fixed point of the third order.

\section{Application: Solving a Class of Third-Order Difference Matrix Equations}

In this section, we apply our main results to the study of a class of third-order difference matrix equations. At first, we start by fixing some notations and recalling some preliminaries.
We will use the symbol $H(N)$ for the set of all $N \times N$ Hermitian matrices. We denote by $P(N)$ the set of all $N \times N$ Hermitian positive definite matrices. Instead of $X \in P(N)$ we will also write $X>0$. Furthermore, $X \geq 0$ means that $X$ is positive semidefinite. As a different notation for $X-$ $Y \succeq 0, X-Z \succeq 0$ and $X \preceq Z \preceq Y$ we will use, respectively, $X \geq Y, X \geq Z$, and $Z \in[X, Y]$. The symbol $\|\cdot\|$ denotes the spectral norm, that is, $\|A\|=\lambda_{\max }^{1 / 2}\left(A^{*} A\right)$, the largest eigenvalue of $A^{*} A$. We denote by $\|\cdot\|_{1}$ the Ky Fan norm defined by $\|A\|_{1}=\sum_{j=1}^{N} s_{j}(A)$, where $s_{j}(A), j=1, \ldots, N$ are the singular values of $A$. For a given $Q \in P(N)$, we define the modified norm $\|\cdot\|_{1, Q}$ given by $\|A\|_{1, Q}=\left\|Q^{1 / 2} A Q^{1 / 2}\right\|_{1}$. The set $H(N)$ endowed with this norm is a complete metric space for any positive definite matrix $Q$. For any $N \times N$ matrix $A$, we denote by $\operatorname{tr}(A)$ the trace of the matrix $A$.

The following lemmas will be useful later.

Lemma 13 (see [18]). Let $A \geq 0$ and $B \geq 0$ be $N \times N$ matrices, then

$$
0 \leq \operatorname{tr}(A B) \leq\|A\| \operatorname{tr}(B) .
$$

Lemma 14 (See [21]). Let $A \in H(N)$ satisfy $-I \prec A \prec I$, then $\|A\|<1$.

Finally, we recall the well-known Schauder fixed-point theorem.

Theorem 15 (The Schauder fixed-point theorem). Let $S$ be a nonempty, compact, and convex subset of a normed vector space. Every continuous function $f: S \rightarrow S$ mapping $S$ into itself has a fixed point.

Now, we consider the class of third-order difference matrix equations:

$$
\begin{aligned}
U_{n+1}= & Q+\sum_{i=1}^{m} A_{i} U_{n} A_{i}-\sum_{i=1}^{m} B_{i} U_{n-1} B_{i} \\
& +\sum_{i=1}^{m} C_{i} U_{n-2} C_{i}, \quad n=2,3, \ldots
\end{aligned}
$$

for given $U_{0}, U_{1}, U_{2}>0$, where $Q>0$ and $A_{i}, B_{i}$, and $C_{i}$ are $N \times N$ Hermitian matrices. This type of difference equations often arises from many areas such as ladder networks [22, 23], dynamic programming $[24,25]$, and control theory [26, 27].

\subsection{A Convergence Result}

Theorem 16. Suppose that

$$
\begin{gathered}
\sum_{i=1}^{m} A_{i} Q A_{i} \prec \frac{Q}{4}, \quad \sum_{i=1}^{m} B_{i} Q B_{i} \prec \frac{Q}{2}, \\
\sum_{i=1}^{m} C_{i} Q C_{i} \prec \frac{Q}{4} .
\end{gathered}
$$

Then, one has the following. 
(i) Equation (72) has one and only one equilibrium point $\widehat{X}>0$.

(ii) $\widehat{X} \in[F(0, Q, 0), F(2 Q, 0,2 Q)]$, where

$$
\begin{gathered}
F(0,2 Q, 0)=Q-2 \sum_{i=1}^{m} B_{i} Q B_{i}, \\
F(2 Q, 0,2 Q)=Q+2 \sum_{i=1}^{m} A_{i} Q A_{i}+2 \sum_{i=1}^{m} C_{i} Q C_{i} .
\end{gathered}
$$

(iii) The sequences $\left(X_{k}\right)$ and $\left(Y_{k}\right)$ defined by $X_{0}=0=Z_{0}$, $Y_{0}=2 Q$, and

$$
\begin{array}{r}
X_{k+1}=Q+\sum_{i=1}^{m} A_{i} X_{k} A_{i}-\sum_{i=1}^{m} B_{i} Y_{k} B_{i}+\sum_{i=1}^{m} A_{i} X_{k} A_{i} \\
Y_{k+1}=Q+\sum_{i=1}^{m} A_{i} Y_{k} A_{i}-\sum_{i=1}^{m} B_{i} X_{k} B_{i}+\sum_{i=1}^{m} A_{i} Y_{k} A_{i} \\
Z_{k+1}=Q+\sum_{i=1}^{m} A_{i} Z_{k} A_{i}-\sum_{i=1}^{m} B_{i} Y_{k} B_{i}+\sum_{i=1}^{m} A_{i} Z_{k} A_{i}, \\
k=0,1,2, \ldots
\end{array}
$$

converge to $\widehat{X}$, and the error estimation is given by

$$
\begin{gathered}
\max \left\{\left\|X_{k+1}-\widehat{X}\right\|_{1, Q},\left\|Y_{k+1}-\widehat{X}\right\|_{1, Q^{\prime}}\left\|Z_{k+1}-\widehat{Z}\right\|_{1, Q}\right\} \\
\leq \frac{\lambda^{k}}{(1-k)} \max \left\{\left\|X_{1}-X_{0}\right\|_{1, Q^{\prime}}\right. \\
\left.\left\|Y_{1}-Y_{0}\right\|_{1, Q^{\prime}}\left\|Z_{1}-Z_{0}\right\|_{1, Q}\right\},
\end{gathered}
$$

for all $k=0,1, \ldots$, where $\lambda$ is a certain constant in $[0,1)$.

(iv) For every $U_{0}, U_{1}, U_{2} \in[0,2 Q]$, every solution $\left\{U_{n}\right\}$ of (72) converges to $\widehat{X}$.

Proof. In order to make the proof easy, we divide it into several steps.

Step 1 . We claim that there exists a unique $(X, Y, Z) \in H(N) \times$ $H(N) \times H(N)$ solution to the system

$$
\begin{aligned}
& X=Q+\sum_{i=1}^{m} A_{i} X A_{i}-\sum_{i=1}^{m} B_{i} Y B_{i}+\sum_{i=1}^{m} C_{i} X C_{i}, \\
& Y=Q+\sum_{i=1}^{m} A_{i} Y A_{i}-\sum_{i=1}^{m} B_{i} X B_{i}+\sum_{i=1}^{m} C_{i} Y C_{i} \\
& Z=Q+\sum_{i=1}^{m} A_{i} Z A_{i}-\sum_{i=1}^{m} B_{i} Y B_{i}+\sum_{i=1}^{m} C_{i} Z C_{i} .
\end{aligned}
$$

Consider the mapping $F: H(N) \times H(N) \times H(N) \rightarrow H(N)$ defined by

$$
F(X, Y, Z)=Q+\sum_{i=1}^{m} A_{i} X A_{i}-\sum_{i=1}^{m} B_{i} Y B_{i}+\sum_{i=1}^{m} C_{i} Z C_{i},
$$

for all $X, Y, Z \in H(N)$. It is clear that $F$ is a mapping having the mixed monotone property with respect to the partial order $\preceq$. Let $X, Y, Z, U, V, W \in H(N)$ such that $X \succeq U, Y \preceq V$, and $Z \geq W$. Using Lemma 13 , we have

$$
\begin{aligned}
& \|F(X, Y, Z)-F(U, V, W)\|_{1, \mathrm{Q}} \\
& =\operatorname{tr}\left(Q^{1 / 2}(F(X, Y, Z)-F(U, V, W)) Q^{1 / 2}\right) \\
& =\operatorname{tr}\left(Q ^ { 1 / 2 } \left(\sum_{i=1}^{m} A_{i} X A_{i}-\sum_{i=1}^{m} B_{i} Y B_{i}+\sum_{i=1}^{m} C_{i} Z C_{i}\right.\right. \\
& -\sum_{i=1}^{m} A_{i} U A_{i}+\sum_{i=1}^{m} B_{i} V B_{i} \\
& \left.\left.+\sum_{i=1}^{m} C_{i} W C_{i}\right) Q^{1 / 2}\right) \\
& =\sum_{i=1}^{m} \operatorname{tr}\left(Q ^ { 1 / 2 } \left(A_{i}(X-U) A_{i}+B_{i}(V-Y) B_{i}\right.\right. \\
& \left.\left.+C_{i}(Z-W) C_{i}\right) Q^{1 / 2}\right) \\
& =\sum_{i=1}^{m} \operatorname{tr}\left(Q^{1 / 2}\left(A_{i}(X-U) A_{i}\right) Q^{1 / 2}\right) \\
& +\operatorname{tr}\left(Q^{1 / 2}\left(B_{i}(V-Y) B_{i}\right) Q^{1 / 2}\right) \\
& +\operatorname{tr}\left(Q^{1 / 2}\left(C_{i}(Z-W) C_{i}\right) Q^{1 / 2}\right) \\
& =\sum_{i=1}^{m} \operatorname{tr}\left(A_{i} Q A_{i}(X-U)\right)+\operatorname{tr}\left(B_{i} Q B_{i}(V-Y)\right) \\
& +\operatorname{tr}\left(C_{i} Q C_{i}(Z-W)\right) \\
& =\sum_{i=1}^{m} \operatorname{tr}\left(A_{i} Q A_{i} Q^{-1 / 2} Q^{1 / 2}(X-U) Q^{1 / 2} Q^{-1 / 2}\right) \\
& +\operatorname{tr}\left(B_{i} Q B_{i} Q^{-1 / 2} Q^{1 / 2}(V-Y) Q^{1 / 2} Q^{-1 / 2}\right) \\
& +\operatorname{tr}\left(C_{i} Q C_{i} Q^{-1 / 2} Q^{1 / 2}(Z-W) Q^{1 / 2} Q^{-1 / 2}\right) \\
& =\sum_{i=1}^{m} \operatorname{tr}\left(Q^{-1 / 2} A_{i} Q A_{i} Q^{-1 / 2} Q^{1 / 2}(X-U) Q^{1 / 2}\right) \\
& +\operatorname{tr}\left(Q^{-1 / 2} B_{i} Q B_{i} Q^{-1 / 2} Q^{1 / 2}(V-Y) Q^{1 / 2}\right) \\
& +\operatorname{tr}\left(Q^{-1 / 2} C_{i} Q C_{i} Q^{-1 / 2} Q^{1 / 2}(Z-W) Q^{1 / 2}\right)
\end{aligned}
$$




$$
\begin{aligned}
= & \operatorname{tr}\left(\sum_{i=1}^{m} Q^{-1 / 2} A_{i} Q A_{i} Q^{-1 / 2} Q^{1 / 2}(X-U) Q^{1 / 2}\right) \\
& +\operatorname{tr}\left(\sum_{i=1}^{m} Q^{-1 / 2} B_{i} Q B_{i} Q^{-1 / 2} Q^{1 / 2}(V-Y) Q^{1 / 2}\right) \\
& +\operatorname{tr}\left(\sum_{i=1}^{m} Q^{-1 / 2} C_{i} Q C_{i} Q^{-1 / 2} Q^{1 / 2}(Z-W) Q^{1 / 2}\right) \\
\leq & \left\|\sum_{i=1}^{m} Q^{-1 / 2} A_{i} Q A_{i} Q^{-1 / 2}\right\|\|X-U\|_{1, Q} \\
& +\left\|\sum_{i=1}^{m} Q^{-1 / 2} B_{i} Q B_{i} Q^{-1 / 2}\right\|\|V-Y\|_{1, Q} \\
& +\left\|\sum_{i=1}^{m} Q^{-1 / 2} C_{i} Q C_{i} Q^{-1 / 2}\right\|\|Z-W\|_{1, Q} \\
\leq & \delta \max \left\{\|X-U\|_{1, Q},\|V-Y\|_{1, Q},\|X-U\|_{1, Q}\right\},
\end{aligned}
$$

where

$$
\begin{gathered}
\delta=\max \left\{\left\|\sum_{i=1}^{m} Q^{-1 / 2} A_{i} Q A_{i} Q^{-1 / 2}\right\|,\right. \\
\left.\left\|\sum_{i=1}^{m} Q^{-1 / 2} B_{i} Q B_{i} Q^{-1 / 2}\right\|,\left\|\sum_{i=1}^{m} Q^{-1 / 2} C_{i} Q C_{i} Q^{-1 / 2}\right\|\right\} .
\end{gathered}
$$

From (73) and Lemma 14, we have $\delta<1$. Thus, the contractive condition of Theorem 5 is satisfied for all $X, Y$, $Z, U, V, W \in H(N)$ with $X \geq U, Y \preceq V$, and $Z \geq W$. Moreover, from (73), we have $X_{0}=Z_{0}=0 \prec F(0,2 Q, 0)$ and $F(2 Q, 0,2 Q)<2 Q=Y_{0}$.

Now, all the hypotheses of Theorem 5 are satisfied. Consequently, there exists $(X, Y, Z) \in H(N) \times H(N) \times H(N)$ solution to (77). Since for every $X, Y, Z \in H(N)$ there is a greatest lower bound and a least upper bound with respect to the partial order $\preceq$, we deduce from Theorem 7 the uniqueness of the solution to (77). Then, our claim holds.

Step 2. We claim that $X=Y=Z=\widehat{X}$.
Since $X_{0}=Z_{0}=0 \prec Y_{0}=2 Q$ (note that $Q$ is a positive definite matrix), applying Theorem 5 , we obtain the equality $X=Y=Z$. This proves our claim.

From Steps 1 and 2, we know that (72) has a unique equilibrium point $\widehat{X} \in H(N)$. Now, we need to prove that $\widehat{X} \in P(N)$. This is the goal of the next step.

Step 3 (proof of (i)-(iii)). Define the mapping $G:[F(0,2 Q$, $0), F(2 Q, 0,2 Q)] \rightarrow H(N)$ by

$$
G X=Q+\sum_{i=1}^{m} A_{i} X A_{i}-\sum_{i=1}^{m} B_{i} X B_{i}+\sum_{i=1}^{m} C_{i} X C_{i}
$$

for all $X \in[F(0,2 Q, 0), F(2 Q, 0,2 Q)]$.

From (73), one can show that $G([F(0,2 Q, 0), F(2 Q, 0$, $2 Q)]) \subseteq[F(0,2 Q, 0), F(2 Q, 0,2 Q)]$. Now, applying the Schauder fixed-point theorem (see Theorem 15), we deduce the existence of a fixed point of $G$ in $[F(0,2 Q, 0)$, $F(2 Q, 0,2 Q)]$. But a fixed point of $G$ is an equilibrium point of (72), and from Step 2, we know that (72) has a unique equilibrium point in $H(N)$. Consequently, $0 \prec F(0,2 Q, 0) \preceq$ $\widehat{X} \preceq F(2 Q, 0,2 Q)$. This proves (i) and (ii). For the proof of (iii), we have only to apply the inequalities (19).

Step 4. Let $U_{0}=0, U_{1}=Q$, and $U_{2}=2 Q$. Then, we have $U_{0}, U_{1}, U_{2} \in[0,2 Q]$, thus by (b) Theorem 5 , every solution $\left\{U_{n}\right\}$ to $(72)$ converges to $\widehat{X}$.

3.2. Numerical Example. Consider a third-order difference matrix equation

$$
U_{n+1}=Q+A U_{n} A-B U_{n-1} B+C U_{n-2} C,
$$

where $Q, A, B, C, U_{0}, U_{1}$, and $U_{2}$ are given by

$$
\begin{gathered}
Q=\left(\begin{array}{lll}
1.5 & 0.3 & 0.3 \\
0.3 & 1.5 & 0.3 \\
0.3 & 0.3 & 1.5
\end{array}\right), \quad A=\left(\begin{array}{ccc}
0.3 & 0.05 & 0.05 \\
0.05 & 0.3 & 0.05 \\
0.05 & 0.05 & 0.3
\end{array}\right), \\
B=\left(\begin{array}{lll}
0.1 & 0.2 & 0.1 \\
0.2 & 0.1 & 0.2 \\
0.1 & 0.2 & 0.1
\end{array}\right), \quad C=\left(\begin{array}{ccc}
0.1 & 0.1 & 0.1 \\
0.1 & 0.1 & 0.1 \\
0.1 & 0.1 & 0.1
\end{array}\right), \\
U_{0}=0, \quad U_{1}=Q, \quad U_{2}=2 Q
\end{gathered}
$$

We are interested to approximate the unique positive equilibrium to (82).

We use Algorithm (iii) of Theorem 16 with $X_{0}=0=Z_{0}$ and $Y_{0}=2 \mathrm{Q}$.

After 35 iterations, we get the unique solution $\widehat{X}$ given by

$$
\begin{gathered}
\widehat{X}=X_{35}=Y_{35}=Z_{35}=\left(\begin{array}{ccc}
1.615643487571 & 0.31874620339355 & 0.33564348757095 \\
0.31874620339355 & 1.5374221323462 & 0.31874620339355 \\
0.33564348757095 & 0.31874620339355 & 1.615643487571
\end{array}\right), \\
U_{35}=\left(\begin{array}{ccc}
1.6156434875817 & 0.31874620340583 & 0.33564348758171 \\
0.31874620340583 & 1.5374221323604 & 0.31874620340583 \\
0.33564348758171 & 0.31874620340583 & 1.6156434875817
\end{array}\right) .
\end{gathered}
$$




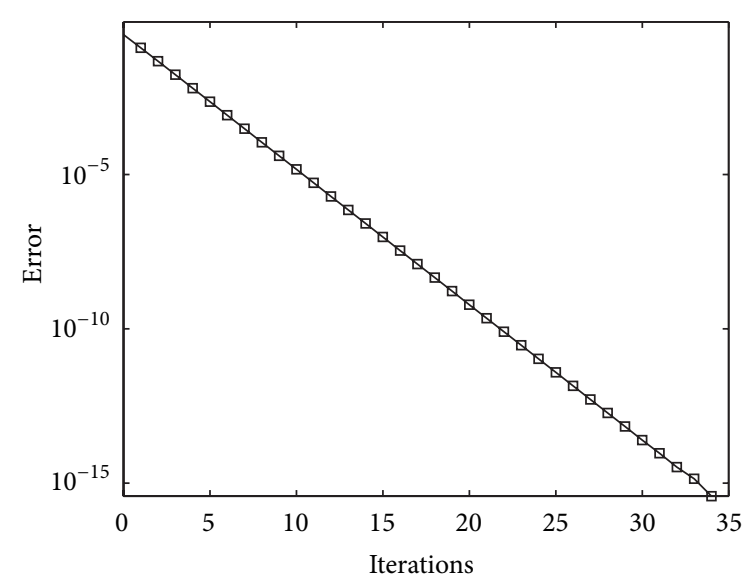

(a)

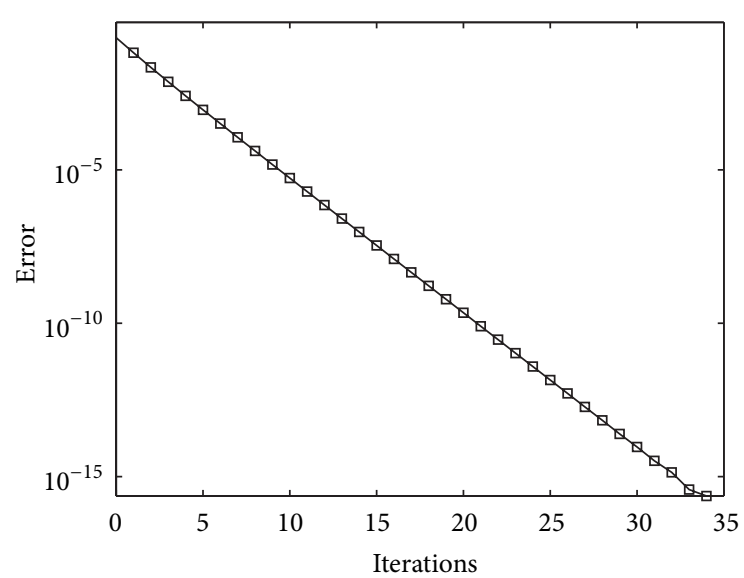

(c)

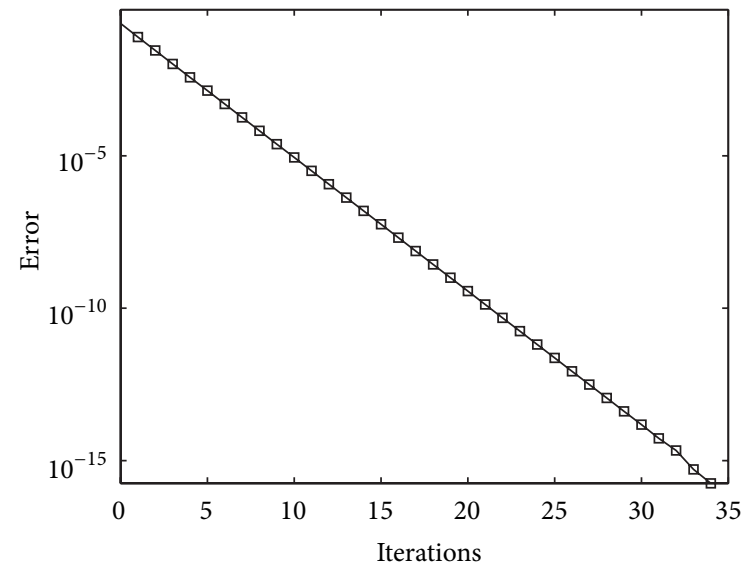

(b)

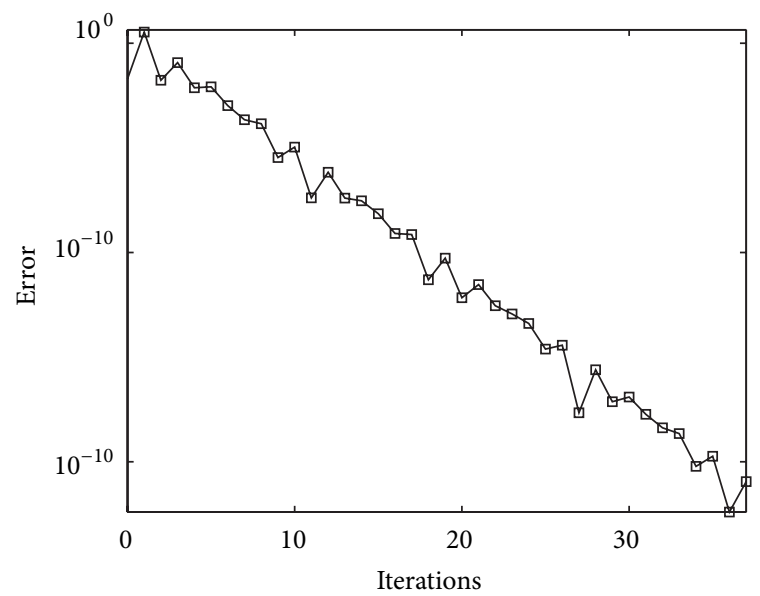

(d)

FIGURE 1: Convergence history for (82).

The residual errors are

$$
\begin{aligned}
R(X)_{35}= & \| X_{35}-\left(Q+A_{1} X_{35} A_{1}+A_{2} X_{35} A_{2}\right. \\
& \left.-B_{1} X_{35} B_{1}-B_{2} X_{35} B_{2}\right) \| \\
= & 3.792 \times 10^{-16}, \\
R(Y)_{35}= & \| Y_{35}-\left(Q+A_{1} Y_{35} A_{1}+A_{2} Y_{35} A_{2}\right. \\
& \left.\quad-B_{1} Y_{35} B_{1}-B_{2} Y_{35} B_{2}\right) \| \\
= & 1.796 \times 10^{-16}, \\
R(Z)_{35}= & \| Z_{35}-\left(Q+A_{1} Z_{35} A_{1}+A_{2} Z_{35} A_{2}\right. \\
& \left.\quad-B_{1} Z_{35} B_{1}-B_{2} Z_{35} B_{2}\right) \| \\
= & 2.351 \times 10^{-16},
\end{aligned}
$$

$$
\begin{aligned}
R(U)_{35}=\| U_{35}-\left(Q+A_{1} U_{35} A_{1}+A_{2} U_{35} A_{2}\right. \\
\left.-B_{1} U_{35} B_{1}-B_{2} U_{35} B_{2}\right) \| \\
=3.352 \times 10^{-11} .
\end{aligned}
$$

The convergence history is given by Figure 1, where (a) corresponds to $\left\|X_{k}-F\left(X_{k}, X_{k}, X_{k}\right)\right\|$, (b) corresponds to $\| Y_{k}-$ $F\left(Y_{k}, Y_{k}, Y_{k}\right) \|$, (c) corresponds to $\left\|Z_{k}-F\left(Z_{k}, Z_{k}, Z_{k}\right)\right\|$, and (d) corresponds to $\left\|U_{k}-F\left(U_{k}, U_{k}, U_{k}\right)\right\|$.

\section{References}

[1] M. R. S. Kulenović and G. Ladas, Dynamics of Second Order Rational Difference Equations, Chapman \& Hall/CRC, Boca Raton, Fla, USA, 2002, With open problems and conjectures.

[2] E. Camouzis and G. Ladas, Dynamics of third-order rational difference equations with open problems and conjectures, vol. 5 of 
Advances in Discrete Mathematics and Applications, Chapman Hall/CRC, Boca Raton, Fla, USA, 2008.

[3] M. R. S. Kulenović and O. Merino, "A global attractivity result for maps with invariant boxes," Discrete and Continuous Dynamical Systems B, vol. 6, no. 1, pp. 97-110, 2006.

[4] R. D. Nussbaum, "Global stability, two conjectures and Maple," Nonlinear Analysis: Theory, Methods \& Applications, vol. 66, no. 5, pp. 1064-1090, 2007.

[5] H. L. Smith, "The discrete dynamics of monotonically decomposable maps," Journal of Mathematical Biology, vol. 53, no. 4, pp. 747-758, 2006.

[6] H. L. Smith, "Global stability for mixed monotone systems," Journal of Difference Equations and Applications, vol. 14, no. 1011, pp. 1159-1164, 2008.

[7] R. P. Agarwal, M. A. El-Gebeily, and D. O’Regan, "Generalized contractions in partially ordered metric spaces," Applicable Analysis, vol. 87, no. 1, pp. 109-116, 2008.

[8] I. Altun and H. Simsek, "Some fixed point theorems on ordered metric spaces and application," Fixed Point Theory and Applications, vol. 2010, Article ID 621469, 17 pages, 2010.

[9] V. Berinde and M. Borcut, "Tripled fixed point theorems for contractive type mappings in partially ordered metric spaces," Nonlinear Analysis: Theory, Methods \& Applications, vol. 74, no. 15, pp. 4889-4897, 2011.

[10] T. Gnana Bhaskar and V. Lakshmikantham, "Fixed point theorems in partially ordered metric spaces and applications," Nonlinear Analysis: Theory, Methods \& Applications, vol. 65, no. 7, pp. 1379-1393, 2006.

[11] A. Brett and M. R. S. Kulenović, "Basins of attraction of equilibrium points of monotone difference equations," Sarajevo Journal of Mathematics, vol. 5, no. 2, pp. 211-233, 2009.

[12] D. Burgić, S. Kalabušić, and M. R. S. Kulenović, "Period-two trichotomies of a difference equation of order higher than two," Sarajevo Journal of Mathematics, vol. 4, no. 1, pp. 73-90, 2008.

[13] L. Cirić, N. Cakić, M. Rajović, and J. S. Ume, "Monotone generalized nonlinear contractions in partially ordered metric spaces," Fixed Point Theory and Applications, vol. 2008, Article ID 131294, 11 pages, 2008.

[14] E. Karapinar, "Couple fixed point theorems for nonlinear contractions in cone metric spaces," Computers \& Mathematics with Applications, vol. 59, no. 12, pp. 3656-3668, 2010.

[15] V. Lakshmikantham and L. Cirić, "Coupled fixed point theorems for nonlinear contractions in partially ordered metric spaces," Nonlinear Analysis: Theory, Methods \& Applications, vol. 70, no. 12, pp. 4341-4349, 2009.

[16] J. J. Nieto and R. Rodríguez-López, "Contractive mapping theorems in partially ordered sets and applications to ordinary differential equations," Order, vol. 22, no. 3, pp. 223-239, 2005.

[17] J. J. Nieto and R. Rodríguez-López, "Existence and uniqueness of fixed point in partially ordered sets and applications to ordinary differential equations," Acta Mathematica Sinica, vol. 23, no. 12, pp. 2205-2212, 2007.

[18] A. C. M. Ran and M. C. B. Reurings, "A fixed point theorem in partially ordered sets and some applications to matrix equations," Proceedings of the American Mathematical Society, vol. 132, no. 5, pp. 1435-1443, 2004.

[19] B. Samet, "Coupled fixed point theorems for a generalized Meir-Keeler contraction in partially ordered metric spaces," Nonlinear Analysis: Theory, Methods \& Applications, vol. 72, no. 12, pp. 4508-4517, 2010.
[20] D. Burgić, S. Kalabušić, and M. R. S. Kulenović, "Global attractivity results for mixed-monotone mappings in partially ordered complete metric spaces," Fixed Point Theory and Applications, vol. 2009, Article ID 762478, 17 pages, 2009.

[21] R. Bhatia, Matrix Analysis, vol. 169 of Graduate Texts in Mathematics, Springer, New York, NY, USA, 1997.

[22] T. Ando, "Limit of iterates of cascade addition of matrices," Numerical Functional Analysis and Optimization, vol. 2, no. 78, pp. 579-289, 1980.

[23] W. N. Anderson, T. D. Morley, and G. E. Trapp, "Ladder networks, fixed points and the geometric mean," Circuits, Systems and Signal Processing, vol. 2, no. 3, pp. 259-268, 1983.

[24] J. C. Engwerda, "On the existence of a positive definite solution of the matrix equation $X+A^{T} X^{-1} A=I$," Linear Algebra and its Applications, vol. 194, pp. 91-108, 1993.

[25] W. Pusz and S. L. Woronowicz, "Functional calculus for sesquilinear forms and the purification map," Reports on Mathematical Physics, vol. 8, no. 2, pp. 159-170, 1975.

[26] B. L. Buzbee, G. H. Golub, and C. W. Nielson, "On direct methods for solving Poisson's equations," SIAM Journal on Numerical Analysis, vol. 7, pp. 627-656, 1970.

[27] W. L. Green and E. W. Kamen, "Stabilizability of linear systems over a commutative normed algebra with applications to spatially-distributed and parameter-dependent systems," SIAM Journal on Control and Optimization, vol. 23, no. 1, pp. 1-18, 1985. 


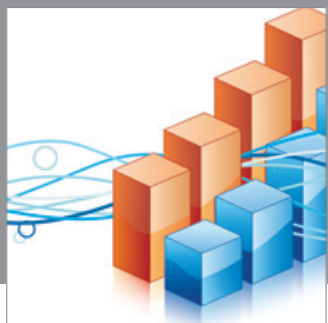

Advances in

Operations Research

mansans

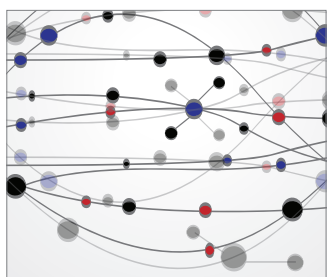

The Scientific World Journal
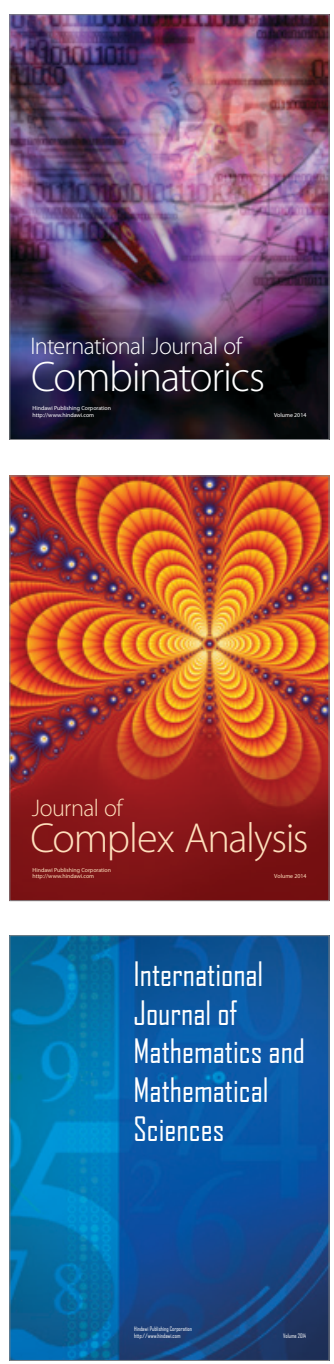
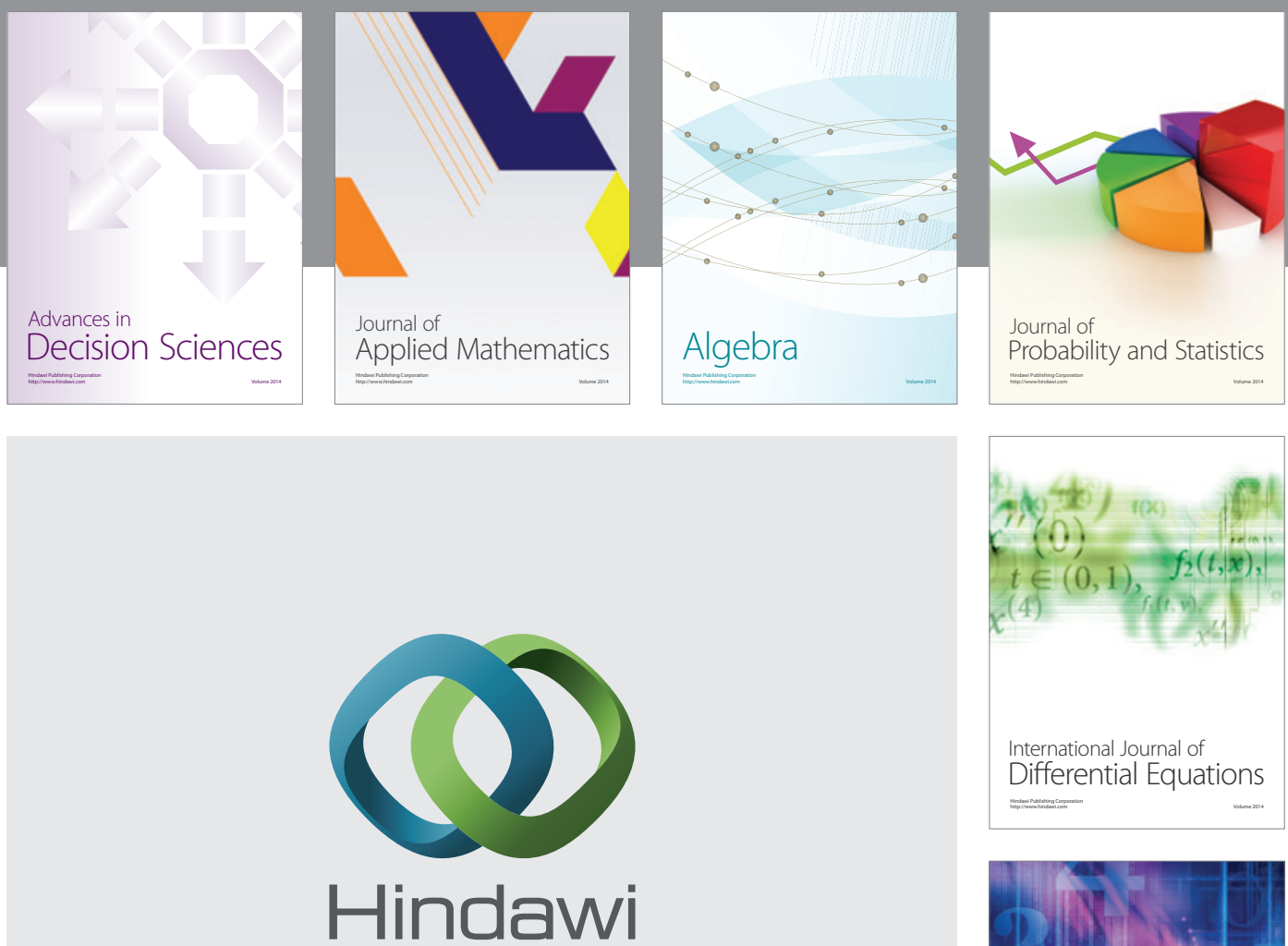

Submit your manuscripts at http://www.hindawi.com
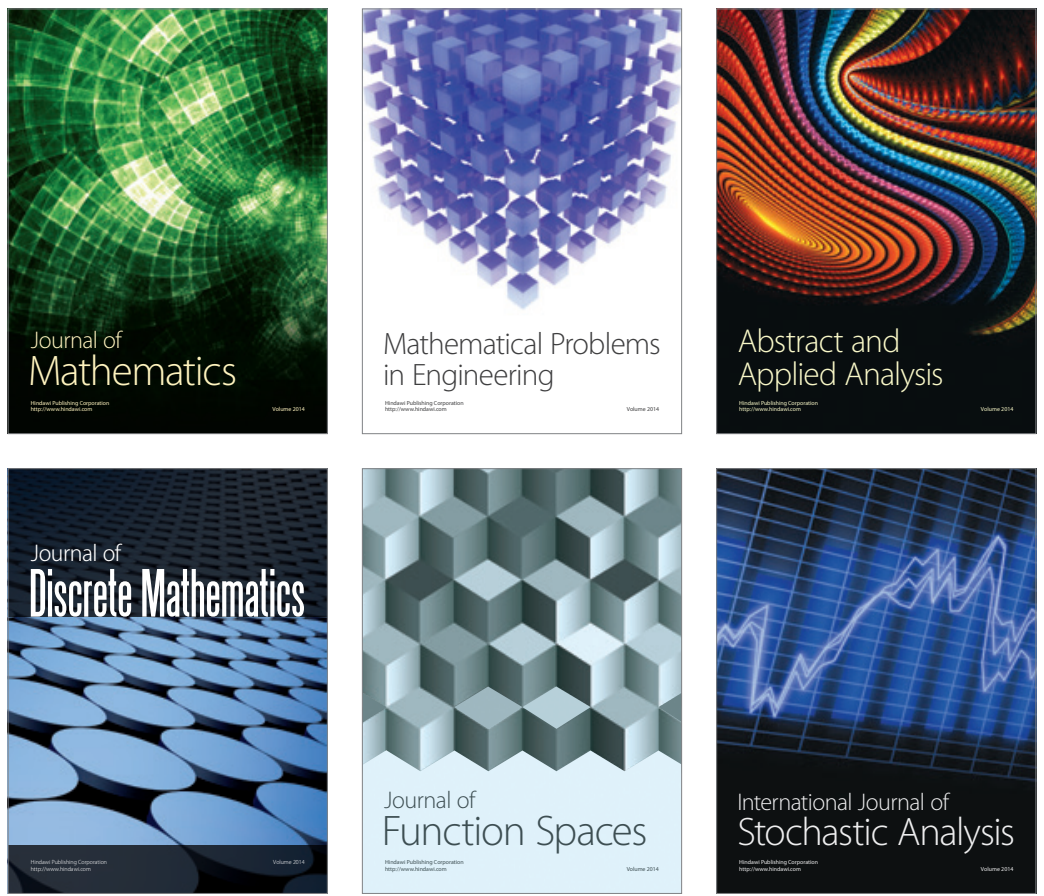

Journal of

Function Spaces

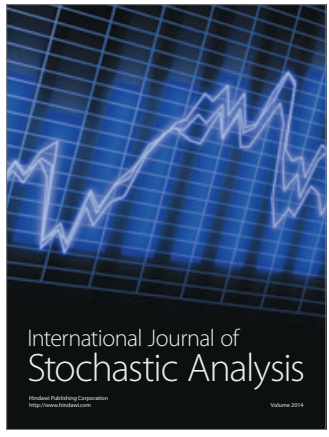

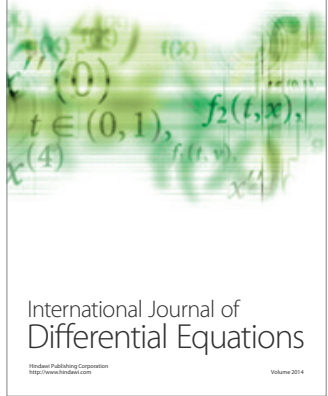
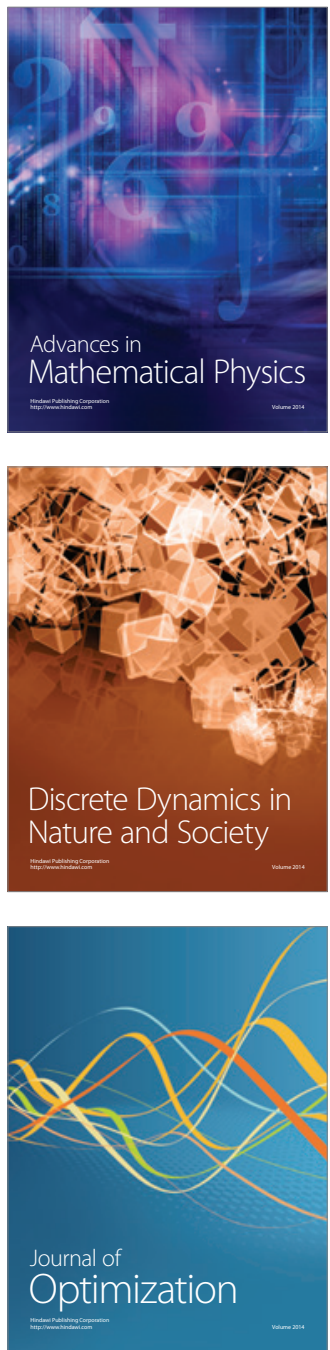